\title{
Article
}

\section{Techno-Economic Analysis of Hydrokinetic Turbines}

\author{
Anurag Kumar ${ }^{1}$, Dr. R.P. Saini²
}

1 Assistant Professor, Mechanical engineering Department, Krishna engineering College, Ghaziabad, India; anurag.technologist@gmail.com

2 Associate Professor, Mechanical engineering Department, Krishna engineering College, Ghaziabad, India; rajsafah@iitr.ac.in

\begin{abstract}
In small-scale hydropower scheme, the most important component is electro-mechanical equipment. Since cost contribution of this component is high because hydrokinetic projects require negligible civil works. Turbine and alternator contribute a major fraction of the hydrokinetic projects. Thus, there is a requirement to estimates the electromechanical equipment cost for a hydrokinetic hydropower scheme. The present paper investigates design parameters of the hydrokinetic turbines and intends to develop cost correlation which depends on most critical parameters of hydropower sites such as velocity and power capacity. In this present work, three zero head turbines are considered including straight blade Darrieus, two Stage Savonius, and Gorlov Helical. The size and cost of major components have been calculated based on material, manufacturing, research and design, and assembly costs. Based on cost and site parameters, cost correlation has been developed. The obtained cost has been validated with available zero head turbines in the market and installed projects. A techno-economic analysis has been carried out to select economical hydrokinetic turbine for river and canal application.
\end{abstract}

Keywords: ultra-low head turbines; cost correlations; Darrieus; Savonius; small hydro energy

\section{Introduction}

Energy is precarious, directly or indirectly, in the entire process of advancement, growth, and endurance of all living beings and it plays a vital role in the socio-economic development and human prosperity of a country. Renewable power generation can help countries meet their sustainable development goals through the provision of access to clean, secure, reliable energy sources solar, wind, and hydropower. Among all renewable energy sources, small hydropower provides a significant amount of economical, clean electricity. Hydrokinetic power generation has a very significant contribution to small hydro development [1-3].

Turbine is considered to be the heart of any hydropower plant, and performance of turbine is very critical. It is a key component to deciding all the parameters of a powerhouse. There are many standard turbines available for small-scale hydro [4]. However, conventional turbines are not technoeconomically viable for many micro hydropower sites. It is found that many attempts are being made to develop the turbine technology for zero head hydropower sites [6-8]. According to the literature review, it is found that techno-economic feasibility of zero head turbines is still a critical area to justify the feasibility of these turbines.

In the present work, Turbines for zero head hydropower installed at various sites have been studied. Some important parameters of turbines and their sizing are discussed. An attempt has been made to estimate the cost of such turbines and cost correlations are developed based on different size turbines up to $100 \mathrm{~kW}$. A techno- economic study for zero head turbines has also been carried out for small-scale micro hydropower. 


\section{Hydro Kinetic Turbines}

Hydrokinetic turbines are kinetic energy conversion devices, which can extract energy from the flowing water. This type of turbine is the completely open type of turbine no casing or cage is required. In comparison to other conventional turbines, no dam and civil structure are required to install hydrokinetic turbines in water. There are a lot of similarities in wind and hydrokinetic energy converters. Hydrokinetic turbines could be an anchor or floated on a pontoon in water. It can be install in very low flow velocity $>0.5 \mathrm{~m} / \mathrm{s}$ [1]. Hydrokinetic turbines are classified as the vertical axis and horizontal axis based on the alignment of the shaft [2]. There are two most common hydrokinetic concepts, axial flow, and cross flow, turbines are used frequently in small-scale hydrokinetic energy conversion. Figure 1 shows the various types of hydrokinetic turbines reported in literatures.

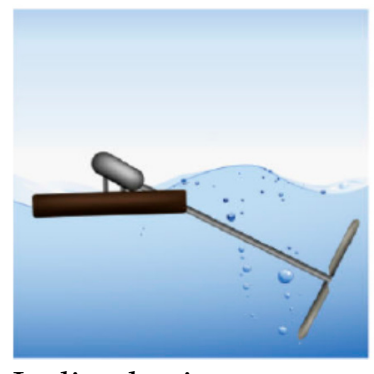

Inclined axis

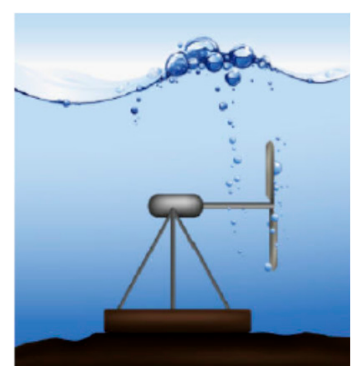

Rigid Mooring

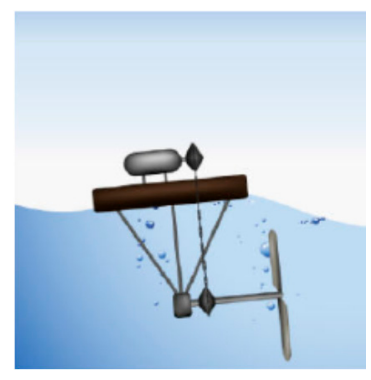

Non-submerged Generator

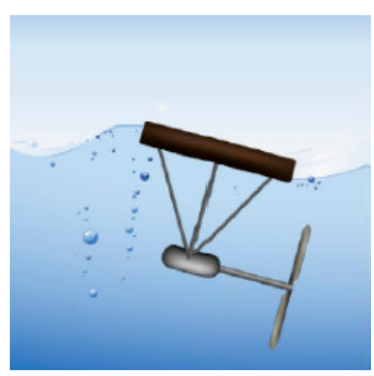

Submerged Generator

Figure 1. horizontal axis hydrokinetic turbine [2]

Darrieus, Savonius, and Gorlov helical type hydrokinetic turbines are mostly used turbine in hydrokinetic projects. However, the inclined axis hydrokinetic turbine has installed in pumping purpose [3]. Keeping in this view, Darrieus, Savonius and Gorlov helical turbine are considered for techno-economic analysis.

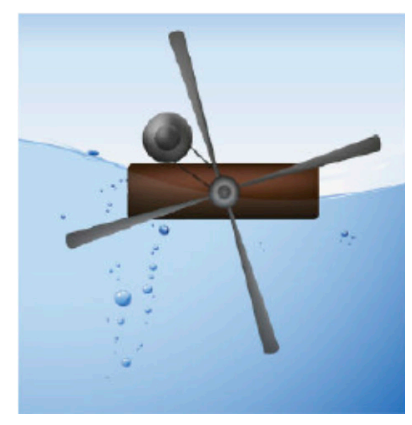

plane axis

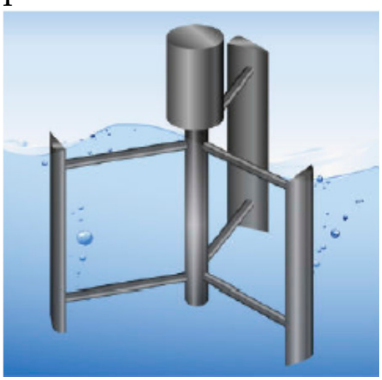

Darrieus
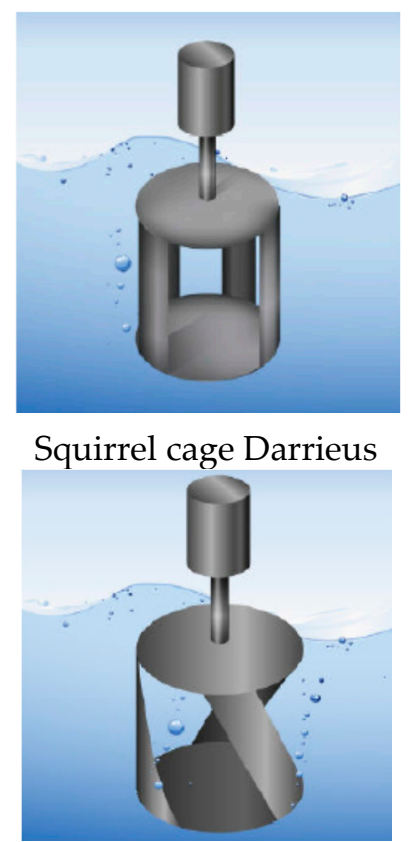

Gorlov

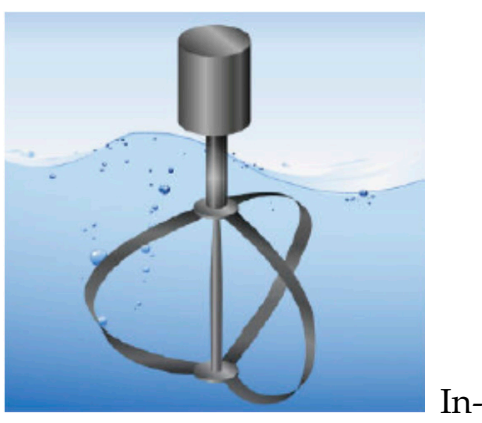

H-Darrieus

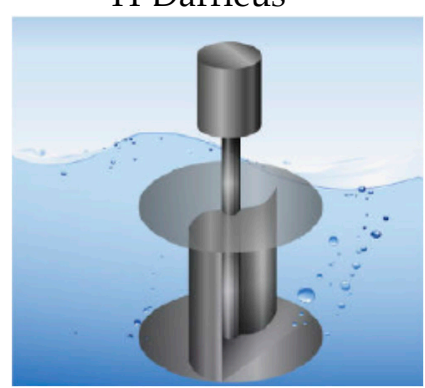

Savonius

Figure 2. Vertical axis hydrokinetic turbines [2] 


\subsection{Components of the hydrokinetic turbine}

The basic components of the hydrokinetic turbine can be typically classified as (i) Blades (ii) Shaft (iii) Supporting arms or end plate (iv) Generator. A typical layout of Darrieus turbine is shown in Figure. 3.

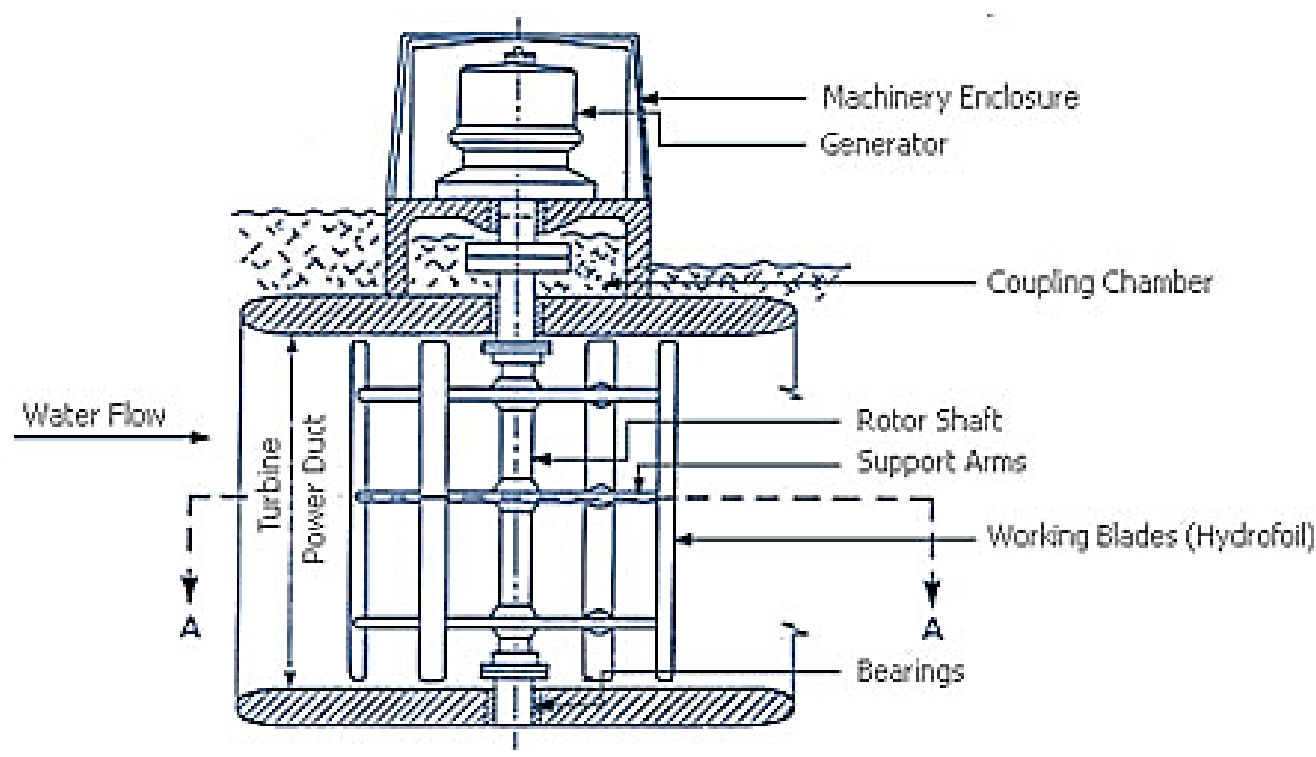

Figure 3. Typical Straight bladed Darrieus Turbine [4]

It can be seen from the Figure.3 blades, supporting arms, rotor shaft, and generator are the main components of typical Darrieus turbine. In the present study, sizing and costing of hydrokinetic turbine has been carried out based on different site condition and critical parameters.

\subsubsection{Design parameters of the hydrokinetic turbines}

Various design parameters have been used to size the zero head turbines. However, some critical parameters have been determined, which decide the precise design of the turbine. Some important parameters are investigated for zero head turbines and given in Table.1 It is found that the important parameters for zero head turbines are Reynolds number, aspect ratio, Tip speed ratio, solidity, angle of attack and velocity of flow. Tip speed ratio of zero head turbine is a very important parameter, which has to decide very carefully to the sizing of rotor blades. It can be seen from the table the solidity (2-3) is highest for Savonius turbine and lowest (0.45-0.50) for Darrieus turbine.

\section{Analysis for Cost Assessment of Hydrokinetic Turbine}

Darrieus, Savonius and Gorlov helical turbines are commonly used turbines as hydrokinetic energy converters and they are considered for analysis. The main component such as blades, shaft, supporting arms, and generator has been considered in the present analysis. Different site conditions have been considered for sizing turbine. Keeping in this view, turbines are sized in 5-100 kW capacity. For each case, different dimensions of the turbine such as height, diameter, blade size, shaft diameter etc. have been calculated using available equations in literature.

Table 1. Typical range of parameters of hydrokinetic turbines

\begin{tabular}{llll}
\hline Parameters & Darrieus turbine & Savonius turbine & Gorlov helical \\
\hline Velocity of flow $(\mathrm{m} / \mathrm{s})$ & $2.0-5.0$ & $2.0-5.0$ & $0.5-5.0$ \\
Depth of water $(\mathrm{m})$ & $0.5-2.5$ & $0.50-0.86$ & $0.35-2.75$ \\
Twist angle $\left(^{\circ}\right)$ & - & $10.0-15.0$ & 60 \\
Angle of attack $\left(\alpha^{\circ}\right)$ & $5.0-15.0$ & $0.5-8.0$ & $15-60$ \\
Tip speed ratio & $4.0-7.0$ & $0.5-0.85$ & $2-2.5$ \\
Lift and drag coefficient & $\mathrm{Cl}_{\mathrm{l}}(0.5-1.5) \&$ & $\mathrm{C}_{\mathrm{d}}(0.1-0.3) \&$ & $\mathrm{C}_{\mathrm{d}}(0.1-0.3) \&$ \\
\hline
\end{tabular}


Solidity $(\sigma)$

Reynolds number (Re)

Power coefficient(Cp)

Max. Efficiency ( $\eta)$

$\mathrm{H} / \mathrm{d}$ ratio (Aspect ratio)

Overlap ratio
$\mathrm{C}_{\mathrm{d}}(0.01-0.2)$

0.45-0.5

$1.5 \times 10^{5}$

0.3-0.45

0.4

$0.5-1.5$

$C_{1}(0.05-0.2)$
$2.0-3.0$
$8 \times 10^{5}-2.5 \times 10^{6}$
$0.20-0.30$
0.25
$1.2-1.8$
$0-0.5$

$\mathrm{C}_{1}(0.05-0.2)$

$\mathrm{Cl}_{1}(0.05-0.2)$

$0.19-0.30$

$4 \times 10^{3}-5 \times 10^{6}$

$0.3-0.45$

0.3

0.5-1.5

\subsection{Sizing of rotor}

Rotor dimensioning relates the power capacity and flow velocity, which would decide the size of the rotor. A power equation of hydrokinetic turbine given as follows [5]:

$\mathrm{P}=0.5 \mathrm{Q} \mathrm{A} \mathrm{V}{ }^{3} \mathrm{Cp}$

Where $\mathrm{Q}$ is the density of water $\left(\mathrm{kg} / \mathrm{m}^{3}\right)$; frontal area of the turbine $\left(\mathrm{m}^{2}\right)$; $\mathrm{V}$ is flow velocity $\left(\mathrm{m}^{3} / \mathrm{s}\right)$; $\mathrm{Cp}$ is the power coefficient of the turbine (a dimensionless quantity). Using the equation 1, swept area calculated with constant power coefficient. The effective area of the Darrieus turbine is a rectangle (i.e. Product of height and diameter) and mathematically, it is given as;

A $=$ h. d

Different height $(\mathrm{h})$ and diameter $(\mathrm{d})$ combinations may produce the same rotor area and therefore the same theoretical power, ultimate performance of the system depends on several more subtle factors. A Selection of height-diameter ratio $\mathrm{h} / \mathrm{d}$, (typical values may range from 0.5 to 1.5 ) would yield values of rotor height and diameter [6]. In this study, the aspect ratio is considered as $\mathrm{h} / \mathrm{d}=1.5$. Using this ratio, we can calculate the height and diameter of the turbine.

\subsection{Design of blade}

After the rotor, another main component is blade, many attempts have been made on theoretical and experimental study of blade design [6-10] and there are outcomes that on increasing the number of blades, the solidity of the turbine increases and induced torque is higher. This reduces the start problem of the turbine. The design of blade airfoil is an open problem because of water turbine experiences large torque variations as a blade. Thus, most common profiles used in Darrieus turbine are NACA 0012, NACA 0015, NACA 0018, and NACA 63-018.

In this work, it was considered NACA 0015 airfoil profile for Reynolds number $1.5 \times 10^{6}$ and its typical cross section has been calculated for the particular chord length shown in Figure 4 . The blade profile is described by $\mathrm{X} / \mathrm{C}$ and $\mathrm{Y} / \mathrm{C}$ ratio where $\mathrm{C}$ is the chord length of the blade and is calculated by following Eq.3 and the twist angle at any point along the blade can be found using Eq. 4. Since these equations depend on $\phi$ (angle of relative water current to the plane of rotation), Eq.5 is required to solve the equations, and its description can be found in Manwell et al. [11].

$$
\begin{aligned}
& C=\frac{8 \pi r / B C_{l}}{1-\operatorname{Cos} \varphi} \\
& \beta=\phi-\alpha \\
& \varphi=\frac{2}{3} \tan ^{-1} 1 / \lambda r \\
& \sigma=\mathrm{BC} / \lambda \\
& \lambda=\omega \mathrm{r} / \mathrm{V} \\
& \text { Where, } \\
& \mathrm{r}=\text { radius or distance of a section on the blade }(\mathrm{mm}) \text {; } \\
& \mathrm{B}=\text { number of blades } \\
& \mathrm{Cl}_{\mathrm{l}}=\text { design lift coefficient } \\
& \Phi=\text { angle of relative water current velocity (deg.) } \\
& \beta=\text { twist angle (deg.) } \\
& \alpha=\text { design angle of attack (deg.) } \\
& \lambda=\text { design tip speed ratio (TSR). } \\
& \sigma=\text { solidity of turbine } \\
& \mathrm{V}=\text { flow velocity }(\mathrm{m} / \mathrm{s})
\end{aligned}
$$


$\omega=$ rotational speed (radian/s)

In Darrieus turbine, we have taken the five number of blades which contributes high solidity $(\sigma)$ $=2.25$, attack angle $(\alpha)=15^{\circ}$ [5], calculated $\beta=14.76, \mathrm{TSR}=2.25$ and Cross section area of airfoil has calculated $360 \mathrm{~mm}^{2}$.

The weight of the blades has been calculated by using Eq. 8; blade length is same as the rotor height. $\mathrm{W}_{\mathrm{b}}=($ No of blades $) \times($ Cross section area of blade $) \times$ (Blade length) $\times$ (Density of material)

3.3 Design of shaft

A shaft is rotating part, which rotates with the same speed of the turbine or higher speed. It is directly connected to the turbine or by a gearbox to meet speed requirement of attached generator. The power delivered to the shaft by some tangential force and the resultant torque (or twisting moment) set up within shaft permits power to be transferred to the generator. The dimension of the shaft can be calculated by using the Eqs.9 and 10 .

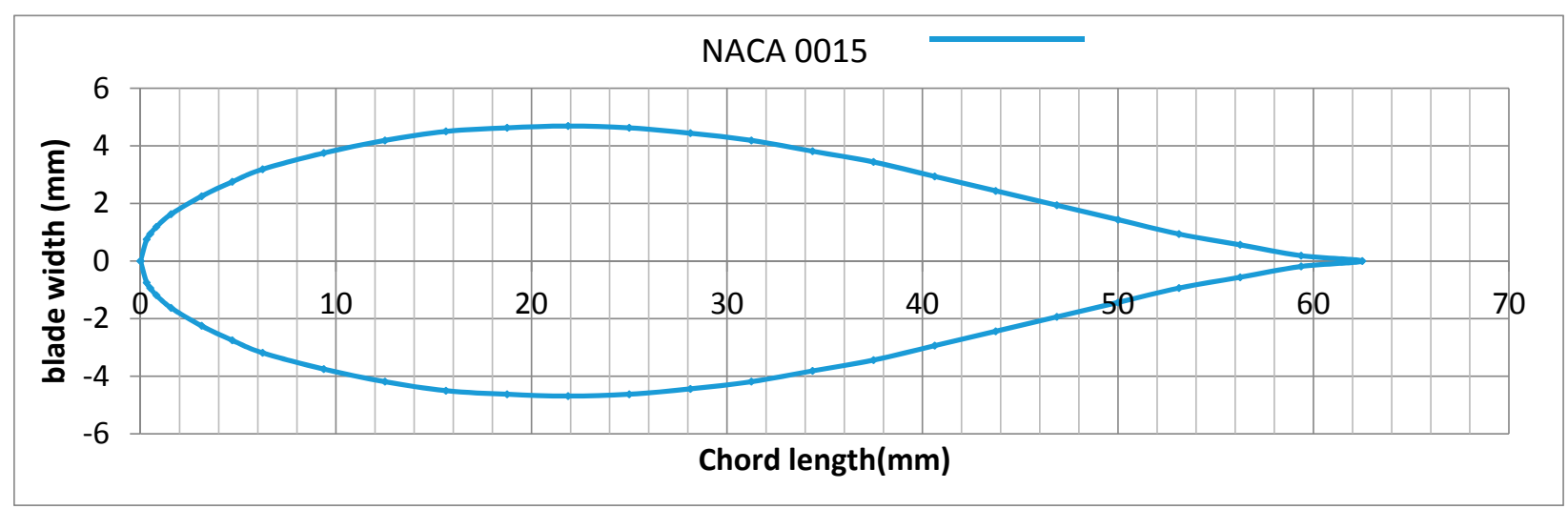

Figure 4. Cross Section profile of NACA 0015 airfoil blade

$\mathrm{P}=2 \pi \mathrm{nT} / 60=\omega \mathrm{T}$

$\mathrm{T}=\left(\pi \mathrm{f}_{\mathrm{s}} \mathrm{D}^{\wedge} 3\right) / 16$

Where,

$\mathrm{T}=$ Torque induced in shaft $(\mathrm{N}-\mathrm{m})$

$\mathrm{n}=$ rotation $(\mathrm{rpm})$

$\mathrm{f}_{\mathrm{s}}=$ stress in shaft $\left(\mathrm{N} / \mathrm{m}^{2}\right)$

$\mathrm{D}=$ Diameter of shaft $(\mathrm{m})$

The length of the shaft for Darrieus turbine kept 1.5 times larger than the turbine height. This extension has been providing for mounting of the gearbox, pulley, and generator fittings. The weight of the shaft can be estimated by using Eq. 10

$\mathrm{Ws}=\pi \mathrm{D} 2 \mathrm{~L} \mathrm{Qm}$

Where $\mathrm{L}$ is the length of shaft $(1.5 \mathrm{xh})$ and @m is density of material use

\subsection{Design of struts}

Struts of the turbine are used to join turbine blade and shaft. They are simply rectangular strips, which support the turbine structure at high water speed and thus provide strength to the turbine. The thickness strips assumed $15 \mathrm{~mm}$ for better strength and low weight turbine. The length of strips is equal to the radius ( $r$ ) of the turbine rotor and width is equal to chord length. No of strips for five bladed Darrieus turbine are calculated as 10 and the weight of all stripes can be estimated by using Eq. 12.

$\mathrm{W}_{\mathrm{st}}=($ length of strip $\times 0.015 \times$ Chord length $) \times \mathrm{Qm}$ 
The total weight of the turbine can be estimated by adding different component's weight and thus cost can be calculated using price of material, which is available in the markets.

\section{Costing of Hydrokinetic Turbines}

The cost of various components of hydrokinetic turbines viz. Rotor, generator and miscellaneous component (bearing, bolts, rivets, etc.) has been determined based on the prevailing rates in the year 2014. The cost of turbine governs the physical size of the turbine and it includes manufacturing cost, research and development cost, assembly cost, and material cost. The sizes of hydrokinetic turbines depend on the velocity of flow and installed capacity. An extensive exercise has been carried out to determine the cost of each case of the turbine at different site conditions. A methodology has been adopted to generate the cost data of the different turbine and it is given in following steps.

- Initially, for a particular installed capacity and site condition, the size of the rotor and the component has been determined.

- Based on size, required material quantity has been calculated in terms of volume/weight.

- Considering the prevailing market price the cost of each component and turbine has been determined.

- Above exercise has been carried out for different installed capacity and site condition for each combination.

\section{Cost Correlation Methodology}

After collecting data, curves have generated by plotting dependable variable on $\mathrm{X}$-axis and cost on Y-axis. Regression analysis is a statistical procedure that minimizes the variability in estimating a variable, which is dependent on other independent variables [12]. It may be the choice for extreme event estimation when a general equation is required for an area. After plotting the data on the chart, the trend line fitted between the points.

By comparing the cost data of various components of turbine corresponding to their dependable parameter, so the power regression has been used to formulate the co-relation. After fitting the power trend line in the chart, the equations were obtained for each component of the layout. The mathematical model for cost items of identified parameters of hydrokinetic turbines has selected and defined as [13];

$C_{(a, b, c)}=a *(P)^{b} *(V)^{c}$

Where, $\mathrm{a}, \mathrm{b}$ and $\mathrm{c}$ are coefficients,

$$
\begin{aligned}
& \mathrm{C}=\text { Cost in rupees }(\mathrm{)} \\
& \mathrm{P}=\text { Installed capacity in kilo Watt }(\mathrm{kW}) \\
& \mathrm{V}=\text { Velocity of upstream flow }(\mathrm{m} / \mathrm{s}) .
\end{aligned}
$$

The installed capacity and velocity of flow are different parameters to estimate and correlate the cost of turbines. The cost of the turbine based on conventional turbine used the head as depended parameters, while the velocity is considered as a depending parameter in the hydrokinetic turbine.

The costing of a turbine includes the ex-works market price of the electromechanical equipment (turbine, alternator, automatic valve, assembly cost material cost, and miscellaneous costs). In this analysis, only turbine material cost, manufacturing cost, assembly cost, design cost, generator cost, and miscellaneous cost (transportation, taxes, documentation etc.) are considered. Manufacturing and design cost of each turbine has been assumed and fixed based on power capacity and all assembly 
cost which are correlated with the sum of material, manufacturing, research and development (R\&D) and generator cost. Generator cost correlation assumptions have been developed based on the experiences and it depends on the power capacity of the turbine. Following assumption is given in Table 2.

Table 2. Assumption used for turbine costing

\begin{tabular}{lc}
\hline Parameters & Value \\
\hline Manufacturing cost & $50,000 / \mathrm{kW}$ \\
Research and development cost & $50,000 / \mathrm{kW}$ \\
Assembly cost & $25 \%$ of $\left(\mathrm{C}_{M}+\mathrm{C}_{\text {R\&D }}+\mathrm{C}_{\text {mat }}+\mathrm{C}_{\text {gen }}\right)$ \\
Miscellaneous cost & $2 \%$ of $\left(\mathrm{C}_{M}+\mathrm{C}_{\mathrm{R} \& \mathrm{D}}+\mathrm{C}_{\text {mat }}+\mathrm{C}_{\text {gen }}\right)$ \\
\hline
\end{tabular}

In the present work, the currency exchange has been taken in May 2014 and its approximate values are taken as follows;

$1 \$=62,1 €=80,1 £=102 \quad$, Inflation Rate $=1.25$ (As per year March 2014)

\subsection{Costing of generator}

Costing of the generator is based on the past data analysis and present cost available in the market. The following data have been collected from the manufacturer and it is given in Table 3 . Cost data have been correlated with a rated capacity of the generator. The cost equation of the generator with power as a depending parameter is developed.

Table 3 Cost of permanent magnet generators up to $100 \mathrm{~kW}$

\begin{tabular}{lll}
\hline Power $(\mathbf{k W})$ & Cost (\$) & Cost ( ) \\
\hline 1 & 480 & 28800 \\
2 & 650 & 39000 \\
3 & 1000 & 60000 \\
4 & 2200 & 132000 \\
5 & 2700 & 162000 \\
10 & 3500 & 210000 \\
25 & 4500 & 270000 \\
50 & 7500 & 450000 \\
100 & 10000 & 600000 \\
\hline
\end{tabular}

Cost data of the generator have been analyzed trough the regression model and best curve fit has been obtained (Figure 5). Cost equation of generator can be given as;

$\mathrm{C}(\mathrm{In} \quad)=(-52.75 \mathrm{P} 2+10670 \mathrm{P}+57609) \quad(\mathrm{kW})$

Where, $\mathrm{P}$ is rated capacity of the generator.

This cost relation has been used to estimate the cost of the turbine system.

There are some metals, which have been used in the manufacturing of the turbine, and their properties and cost are given in Table 4 . As seen from the Table 4, copper alloys have very dense material, which is used rarely for turbine vanes. It has been used mainly for fixing of turbine parts and assembly purpose. 


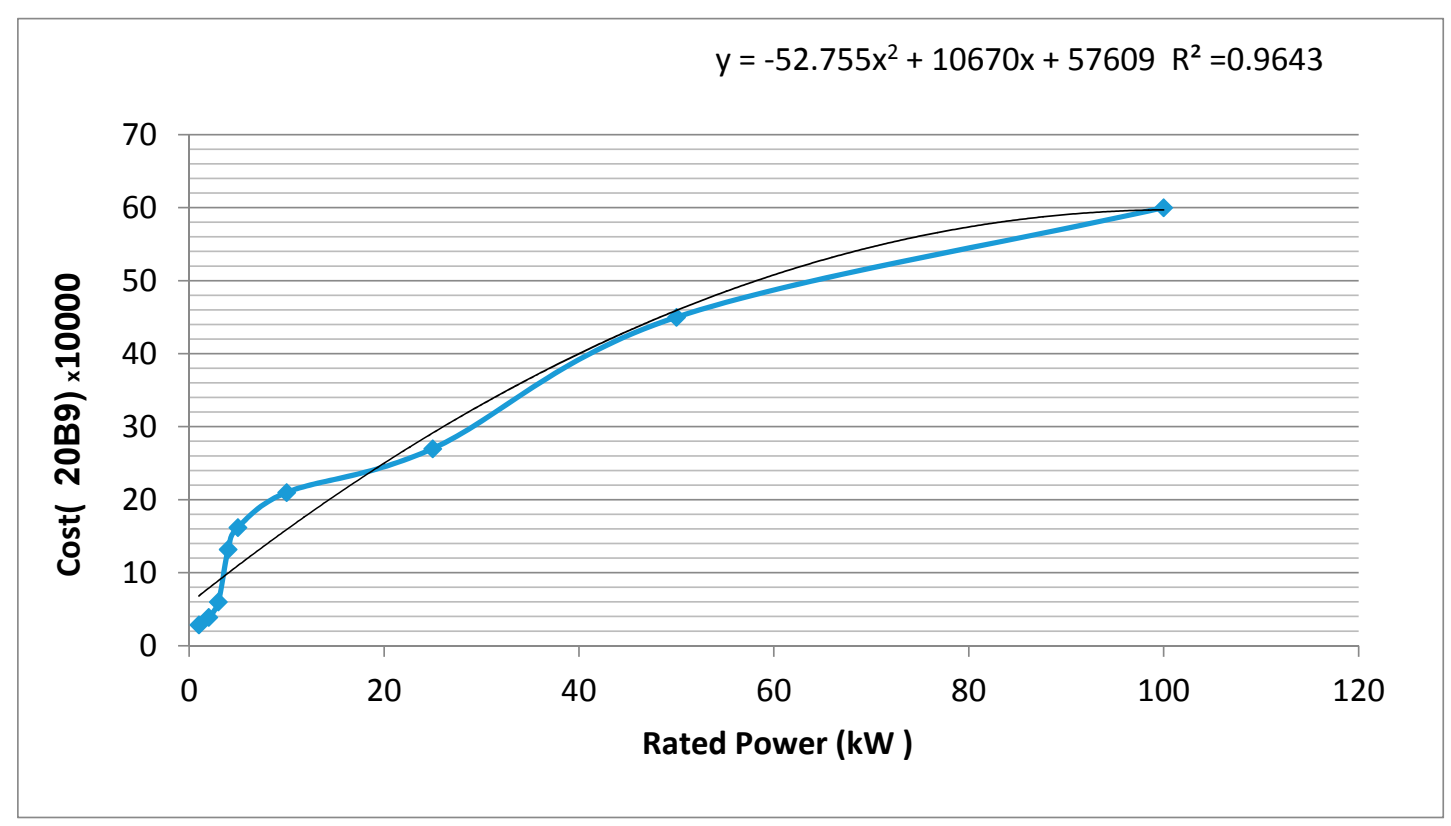

Figure 5. Cost relation of generator up to $100 \mathrm{~kW}$

Table 4. Properties and cost of different metals [14]

\begin{tabular}{|l|l|l|l|}
\hline Material Type & cost ( ) & Density $\left(\mathbf{k g} / \mathbf{m}^{3}\right)$ & $\begin{array}{l}\text { Ultimate stress } \\
(\mathbf{M P a})\end{array}$ \\
\hline Aluminum alloy (7075-T6) & 131.76 & 2700 & 570 \\
\hline Steel, mild 1020 & 36.6 & 7800 & 380 \\
\hline Steel, stainless austenitic 304 & 197.64 & 7800 & 60 \\
\hline Copper alloys & 164.7 & 8300 & 720 \\
\hline
\end{tabular}

\subsubsection{Costing of Darrieus, Savonius and Gorlov helical turbine}

Cost calculations have been worked out for various combinations of power and velocity as given in Table 5. The cost correlation of the Darrieus turbine has been developed by linear regression. Different coefficients values for Darrieus turbine correlation are developed and given as: $\mathrm{a}=272392.68, \mathrm{~b}=-0.0641, \mathrm{c}=-0.0076, \mathrm{R}^{2}=0.9934$

Formulation of the cost equation is given in Figure 6 and 7. The linear regression line has been drawn out in MS-Excel software.

$C_{\text {Darrieus }}=272392.68 \times P^{-0.0641} \times V^{-0.0076}$

Figure 6 shows the relationship between the power capacity and the cost of turbine per $\mathrm{kW}$. Which established and regression line has been drawn to find out the coefficient $(c=-0.0641)$. After another plot (Figure. 7) has been established between, the $\mathrm{C} / \mathrm{P}^{n}$ and velocity and coefficient $\mathrm{b}$ and $\mathrm{a}$ are found. All plots contain logarithmic values with a linear plot. Generated correlations used to carry out the techno-economic analysis of Darrieus turbine.

The correlations obtained which facilitate the determination of the cost of the different turbine (including generator set) from easily available hydropower site data: flow rate, the velocity of flow. These expressions have been differentiated for most common type of zero head turbine. Based on the 
similar exercise, the cost correlation of Savonius and Gorlov helical turbine are developed and summary of expression and constants is given in Table 6 .

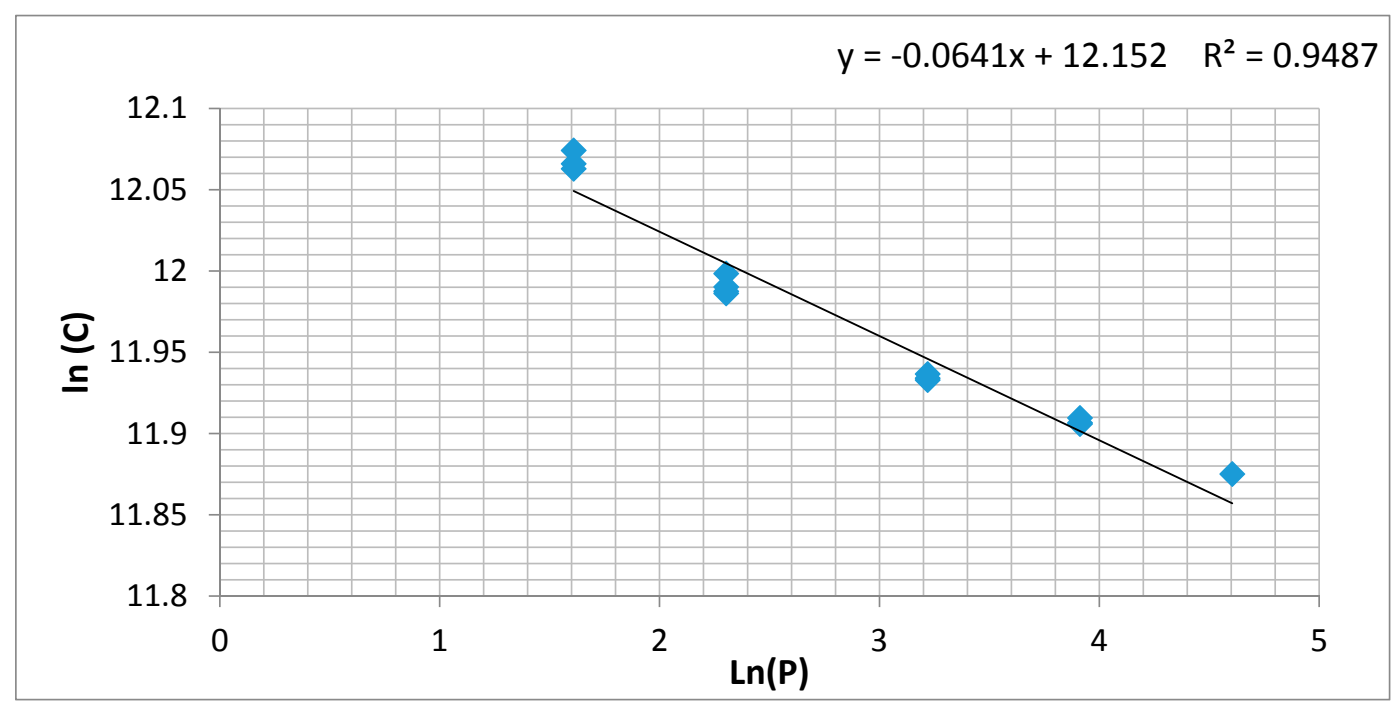

Figure 6. Relation between cost and Power of Darrieus turbine

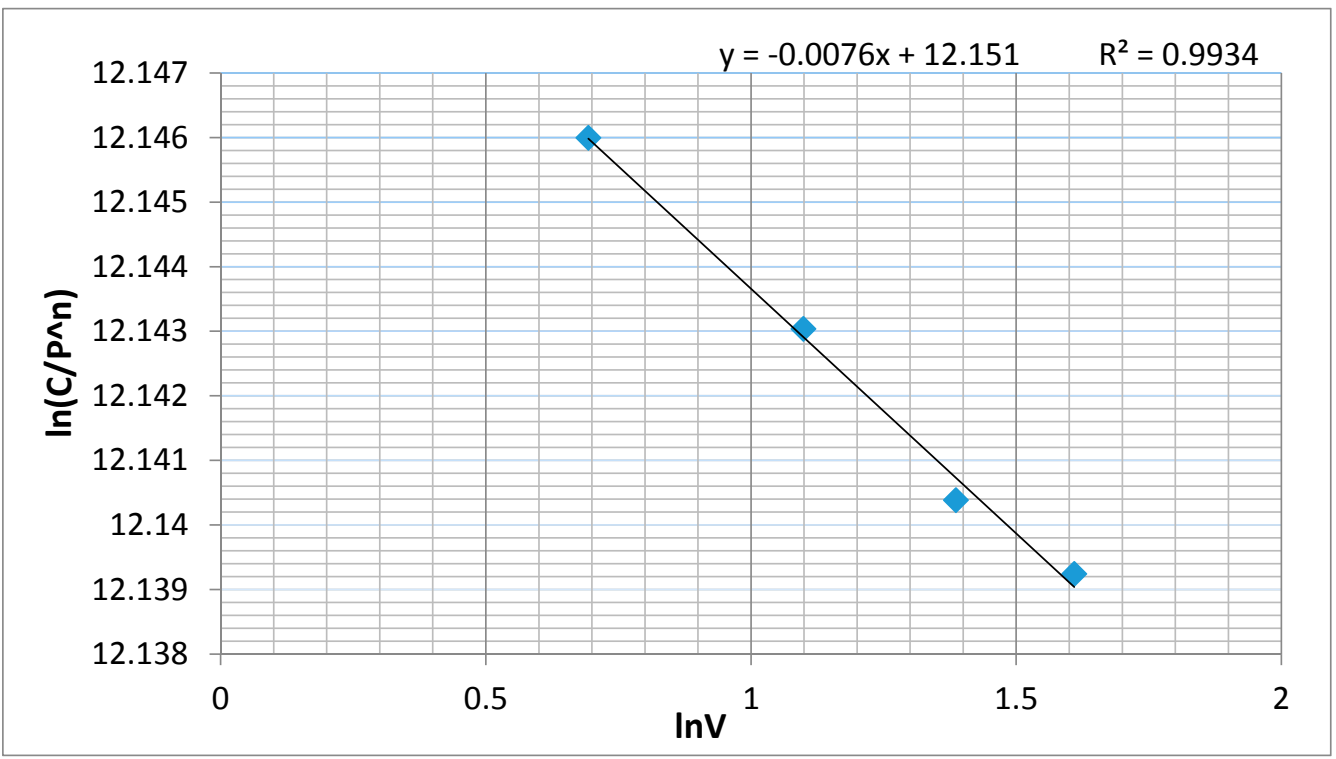

Figure 7. Relation between C/Pn and velocity of Darrieus turbine

Table 5. Quantities and cost of Darrieus turbine components at different combinations of velocity and capacity.

\begin{tabular}{|c|c|c|c|c|c|c|c|c|c|c|c|c|c|c|c|c|}
\hline \multirow{3}{*}{$\begin{array}{l}\mathbf{P} \\
(\mathbf{k W})\end{array}$} & \multirow{3}{*}{$\begin{array}{l}\mathrm{V} \\
(\mathrm{m} / \mathrm{s})\end{array}$} & \multirow{3}{*}{$\begin{array}{l}\text { A } \\
\left(m^{2}\right)\end{array}$} & \multirow{3}{*}{$\begin{array}{l}\mathrm{H} \\
(\mathrm{m})\end{array}$} & \multirow{3}{*}{$\begin{array}{l}\mathrm{R} \\
(\mathrm{m})\end{array}$} & \multirow{2}{*}{\multicolumn{2}{|c|}{$\begin{array}{l}\text { Weight Cost } \\
\text { of Bladeblades }\end{array}$}} & \multirow{3}{*}{$\begin{array}{l}\text { ofWeight } \\
\text { of struts } \\
\text { (Wst) }\end{array}$} & \multicolumn{2}{|c|}{ Cost ofWs } & \multirow[t]{3}{*}{ Cs } & \multirow{3}{*}{$\begin{array}{l}\text { material } \\
\text { cost }(\mathrm{CM})\end{array}$} & \multirow{3}{*}{ Cgen } & \multirow{3}{*}{$\begin{array}{l}\text { Assembly } \\
\text { cost }\end{array}$} & \multirow{3}{*}{$\begin{array}{l}\text { C } \\
\text { miscellaneous }\end{array}$} & \multirow{3}{*}{ Total cost } & \multirow{3}{*}{$\begin{array}{l}\text { Cost per } \\
\text { kW }\end{array}$} \\
\hline & & & & & & & & struts & & & & & & & & \\
\hline & & & & & $(\mathrm{Wb})$ & $(\mathrm{Cb})$ & & (Cst) & & & & & & & & \\
\hline 5 & 1 & 28.57 & 4.36 & 3.27 & 21.21 & 2863 & 110.5 & 14914 & 315 & 15765 & 50314 & 13879 & 8103367 & 137822 & 930301 & 186060 \\
\hline 5 & 2 & 3.57 & 1.54 & 1.16 & 7.50 & 1012 & 39.1 & 5273 & 35 & 1756 & 12061 & 13879 & 897629 & 130172 & 878660 & 175732 \\
\hline 10 & 2 & 7.14 & 2.18 & 1.64 & 10.61 & 1432 & 55.2 & 7457 & 99 & 4966 & 20782 & 18586 & 5180997 & 241329 & 1628973 & 162897 \\
\hline 25 & 2 & 17.86 & 3.45 & 2.59 & 16.77 & 2264 & 87.3 & 11790 & 393 & 19629 & 50524 & 31239 & 3429438 & 572584 & 3864939 & 154598 \\
\hline
\end{tabular}


10 of 15

\begin{tabular}{llllllllllllllll}
\hline $\mathbf{5 0}$ & 2 & 35.71 & 4.88 & 3.66 & 23.71 & 3201 & 123.5 & 16674 & 1110 & 55518 & 113091 & 474368838119 & 1117492 & 7543070 & 150861 \\
\hline $\mathbf{5}$ & 3 & 1.06 & 0.84 & 0.63 & 4.08 & 551 & 21.3 & 2870 & 10 & 486 & 5861 & 13879896699 & 128932 & 870290 & 174058 \\
\hline $\mathbf{1 0}$ & 3 & 2.12 & 1.19 & 0.89 & 5.77 & 779 & 30.1 & 4059 & 28 & 1375 & 9320 & 185865179278 & 239037 & 1613500 & 161350 \\
\hline $\mathbf{2 5}$ & 3 & 5.29 & 1.88 & 1.41 & 9.13 & 1232 & 47.5 & 6418 & 109 & 5436 & 19629 & 312393424803 & 566404 & 3823230 & 152929 \\
\hline $\mathbf{5 0}$ & 3 & 10.58 & 2.66 & 1.99 & 12.91 & 1743 & 67.2 & 9076 & 307 & 15375 & 39291 & 474368827049 & 1102732 & 7443440 & 148869 \\
\hline $\mathbf{1 0 0}$ & 3 & 21.16 & 3.76 & 2.82 & 18.26 & 2464 & 95.1 & 12836 & 870 & 43487 & 88181 & 6149221605465 & 2140621 & 14449189 & 144492 \\
\hline $\mathbf{5}$ & 4 & 0.45 & 0.55 & 0.41 & 2.65 & 358 & 13.8 & 1864 & 4 & 196 & 3627 & 13879896364 & 128485 & 867273 & 173455 \\
\hline $\mathbf{1 0}$ & 4 & 0.89 & 0.77 & 0.58 & 3.75 & 506 & 19.5 & 2636 & 11 & 553 & 5543 & 185865178711 & 238282 & 1608401 & 160840 \\
\hline $\mathbf{2 5}$ & 4 & 2.23 & 1.22 & 0.91 & 5.93 & 800 & 30.9 & 4169 & 44 & 2186 & 10732 & 312393423469 & 564625 & 3811219 & 152449 \\
\hline $\mathbf{5 0}$ & 4 & 4.46 & 1.73 & 1.29 & 8.38 & 1132 & 43.7 & 5895 & 124 & 6183 & 19815 & 474368824127 & 1098837 & 7417147 & 148343 \\
\hline $\mathbf{1 0 0}$ & 4 & 8.93 & 2.44 & 1.83 & 11.86 & 1601 & 61.8 & 8337 & 350 & 17487 & 41137 & 6149221598409 & 2131212 & 14385681 & 143857 \\
\hline $\mathbf{5}$ & 5 & 0.23 & 0.39 & 0.29 & 1.90 & 256 & 9.9 & 1334 & 2 & 96 & 2530 & 13879896199 & 128266 & 865793 & 173159 \\
\hline $\mathbf{1 0}$ & 5 & 0.46 & 0.55 & 0.41 & 2.68 & 362 & 14.0 & 1886 & 5 & 273 & 3782 & 185865178447 & 237929 & 1606023 & 160602 \\
\hline $\mathbf{2 5}$ & 5 & 1.14 & 0.87 & 0.65 & 4.24 & 573 & 22.1 & 2983 & 22 & 1078 & 6951 & 312393422902 & 563869 & 3806114 & 152245 \\
\hline $\mathbf{5 0}$ & 5 & 2.29 & 1.23 & 0.93 & 6.00 & 810 & 31.2 & 4218 & 61 & 3050 & 12117 & 474368822973 & 1097297 & 7406755 & 148135 \\
\hline $\mathbf{1 0 0}$ & 5 & 4.57 & 1.75 & 1.31 & 8.48 & 1145 & 44.2 & 5966 & 173 & 8627 & 23606 & 6149221595779 & 2127706 & 14362013 & 143620
\end{tabular}

The correlations obtained which facilitate the determination of the cost of the different turbine (including generator set) from easily available hydropower site data: flow rate, the velocity of flow. These expressions differentiate the most common type of zero head turbines. Based on the similar exercise, the cost correlation of Savonius and Gorlov helical turbine are developed and summary of expression and constant is given in Table 6.

Table 6. Summary of cost correlation of zero head turbine

\begin{tabular}{lrllll}
\hline Turbine Type & Equation for cost per/kW & a & b & c & $\mathrm{R}^{2}$ \\
\hline Darrieus & $\mathbf{2 7 2 3 9 2 . 6 8} \times \boldsymbol{P}^{-\mathbf{0 . 0 6 4 1}} \times \boldsymbol{V}^{-\mathbf{0 . 0 0 7 6}}$ & 272392.68 & -0.0641 & -0.0076 & 0.99 \\
Savonius & $\mathbf{2 4 9 1 9 7 . 2 4} \times \boldsymbol{P}^{-\mathbf{0 . 0 7 4 8}} \times \boldsymbol{V}^{-\mathbf{0 . 0 8 4 8}}$ & 249197.24 & -0.748 & -0.848 & 0.50 \\
Gorlov helical & $\mathbf{2 5 7 8 1 5 . 6 3} \times \boldsymbol{P}^{-\mathbf{0 . 0 9 4 1}} \times \boldsymbol{V}^{-\mathbf{0 . 1 1 8 3}}$ & 257815.63 & -0.0941 & -0.1183 & 0.647 \\
\hline
\end{tabular}

Table 7. Cost Data of different Turbines from Manufacturers

\begin{tabular}{|c|c|c|c|c|c|}
\hline Manufacturer & Turbine type & $\begin{array}{l}\text { Turbine } \\
(\mathrm{kW})\end{array}$ & $\begin{array}{l}\text { Cost of } \\
\text { turbine(per } \\
k W) \text { INR }\end{array}$ & $\begin{array}{l}\text { Flow } \\
\text { velocity } \\
\text { range }(\mathrm{m} / \mathrm{s})\end{array}$ & $\mathrm{Cp} / \mathrm{n}$ \\
\hline \multirow{6}{*}{$\begin{array}{l}\text { New Energy } \\
\text { Corp. Inc. }\end{array}$} & \multirow{6}{*}{$\begin{array}{l}\text { Darrieus type } \\
\text { straight blade }\end{array}$} & 5 & 354200 & \multirow{6}{*}{$1.5-3.0$} & \multirow{6}{*}{$\begin{array}{l}0.40 \\
-0.45\end{array}$} \\
\hline & & 5(Low RPM ) & 368900 & & \\
\hline & & 10 & 322400 & & \\
\hline & & 25 & 334800 & & \\
\hline & & 125 & 148800 & & \\
\hline & & 250 & 148800 & & \\
\hline hydro volts & & 5 & 248000 & $1.5-3.0$ & 0.3 \\
\hline
\end{tabular}




\begin{tabular}{llcccc} 
& $\begin{array}{l}\text { Savonius } \\
\text { horizontal }\end{array}$ & 25 & 124000 & & \\
Gorlov helical & Gorlov helical & 0.7 & 37200 & $0.67-2.58$ & 0.35 \\
\hline
\end{tabular}

Cost equations obtained for hydrokinetic turbines have been validated among hydropower equipment companies working in design and assembly of the hydro turbines for small-scale hydropower plants and data has been collected related to their cost and specification of turbines are given in Table 7. It is found that all cost correlations have less deviation from the standard turbine, which has been considered in the present study. The simulated results and the actual cost of turbine have been analyzed and deviated errors have been calculated for selected turbines. The details of the validation results and deviated is given in Table 8 and comparison of simulated cost and the actual cost of turbine has been analyzed and shown in Figure 8.

Table 8. Errors Incurred using cost correlations of different turbines

\begin{tabular}{|c|c|c|c|}
\hline \multirow{2}{*}{$\mathrm{P}(\mathrm{kW})$} & \multicolumn{3}{|l|}{ Darrieus } \\
\hline & Actual cost ( ) & Simulated cost ( ) & Error $(\%)$ \\
\hline 5 & 354200 & 284448.42 & 19.69 \\
\hline 10 & 322400 & 255181.68 & 20.85 \\
\hline 25 & 334800 & 260538.14 & 22.18 \\
\hline 50 & 180690 & 148699.40 & 17.70 \\
\hline \multirow[t]{2}{*}{100} & 148800 & 143653.36 & 3.46 \\
\hline & \multicolumn{3}{|l|}{ Savonius } \\
\hline 5 & 248000 & 215479.35 & 13.11 \\
\hline \multirow[t]{2}{*}{25} & 124000 & 140417.18 & -13.24 \\
\hline & \multicolumn{3}{|l|}{ Gorlov helical } \\
\hline 5 & 372000 & 323165.08 & 13.13 \\
\hline
\end{tabular}




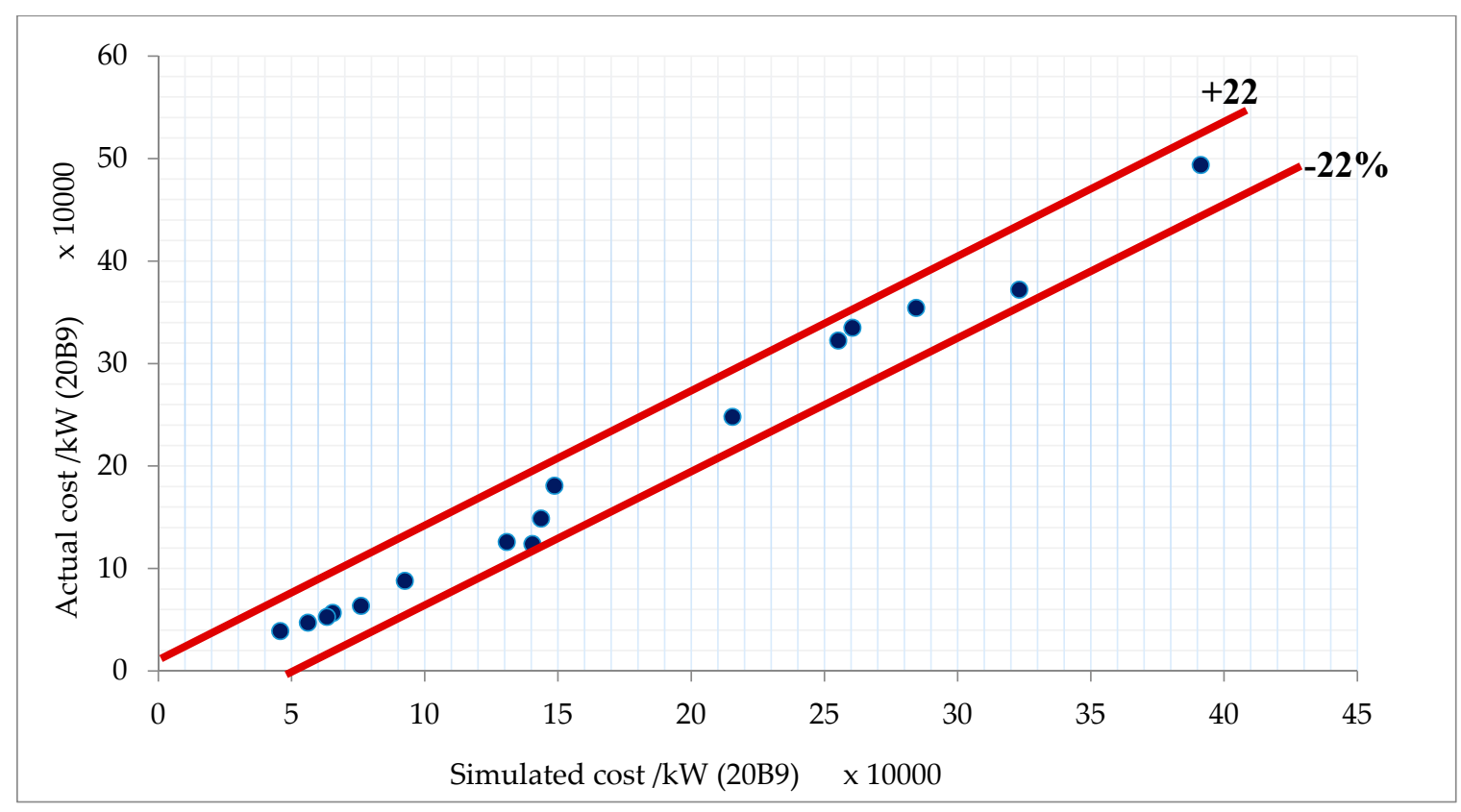

Figure 8. Comparison of total turbine cost per $\mathrm{kW}$ as analyzed with collected turbine data

\section{Techno-Economic Analysis of Hydrokinetic Turbines}

In the present work, sizing and costing have been worked out for five blades straight Darrieus turbine. Cost calculation of different size turbine is determined and their correlation has been developed. Variation of cost per $\mathrm{kW}$ of different power capacity is shown in Figure 9. As it is seen in Figure 9., $5 \mathrm{~kW}$ turbine cost is high at a low velocity of flow $2 \mathrm{~m} / \mathrm{s}$ and minimum at high flow velocity $5 \mathrm{~m} / \mathrm{s}$. it is found as similar data lines for other capacities Darrieus turbines. The higher capacity turbine has high cost than the lower capacity at same velocity range. It can be seen from Figure 10 that small turbine has high cost at low velocity and less cost at high velocity.

The Large turbine is costly at very low velocity $0.5 \mathrm{~m} / \mathrm{s}$ but has lesser cost at high velocity. The cost curve of a larger area of the turbine is also discussed, which is not available for Darrieus turbine range.

A similar analysis has been carried out for Savonius and Gorlov helical turbine. It is observed that the low capacity Savonius turbine cost is highest at $2 \mathrm{~m} / \mathrm{s}$ (i.e. 215479), which is higher than the Darrieus turbine ( 217000) at same flow speed. The turbine cost decreases as the flow velocity increases at the same capacity turbine. An important thing has been observed that the higher capacity turbine has no power generation at low speed and having velocity range $3-5 \mathrm{~m} / \mathrm{s}$ for $100 \mathrm{~kW}$ turbine while $2-5$ for $5 \mathrm{~kW}$ turbine. However, the cost is higher for low capacity turbine than higher capacity turbine at the same velocity. The small size Savonius turbine having area $0.23 \mathrm{~m}^{2}$ able to work on only 5 to $6 \mathrm{~m} / \mathrm{s}$ flow velocity and large size Savonius turbine having area $10-20 \mathrm{~m}^{2}$ can work 1.3 to $4.5 \mathrm{~m} / \mathrm{s}$ velocity range but the cost of this turbine is very high at low capacity. 


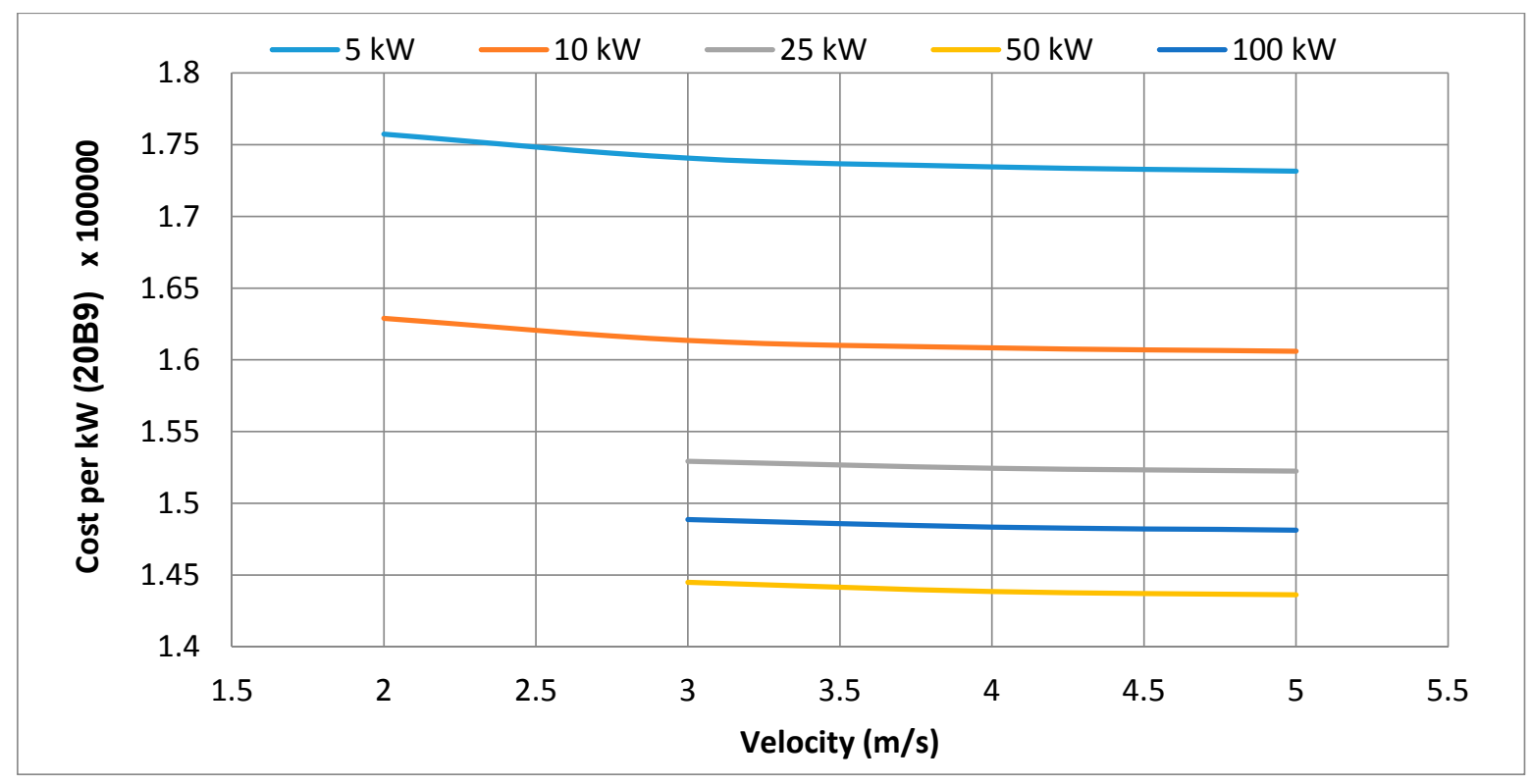

Figure 9. Cost variation of Darrieus turbine with flow velocity at constant power

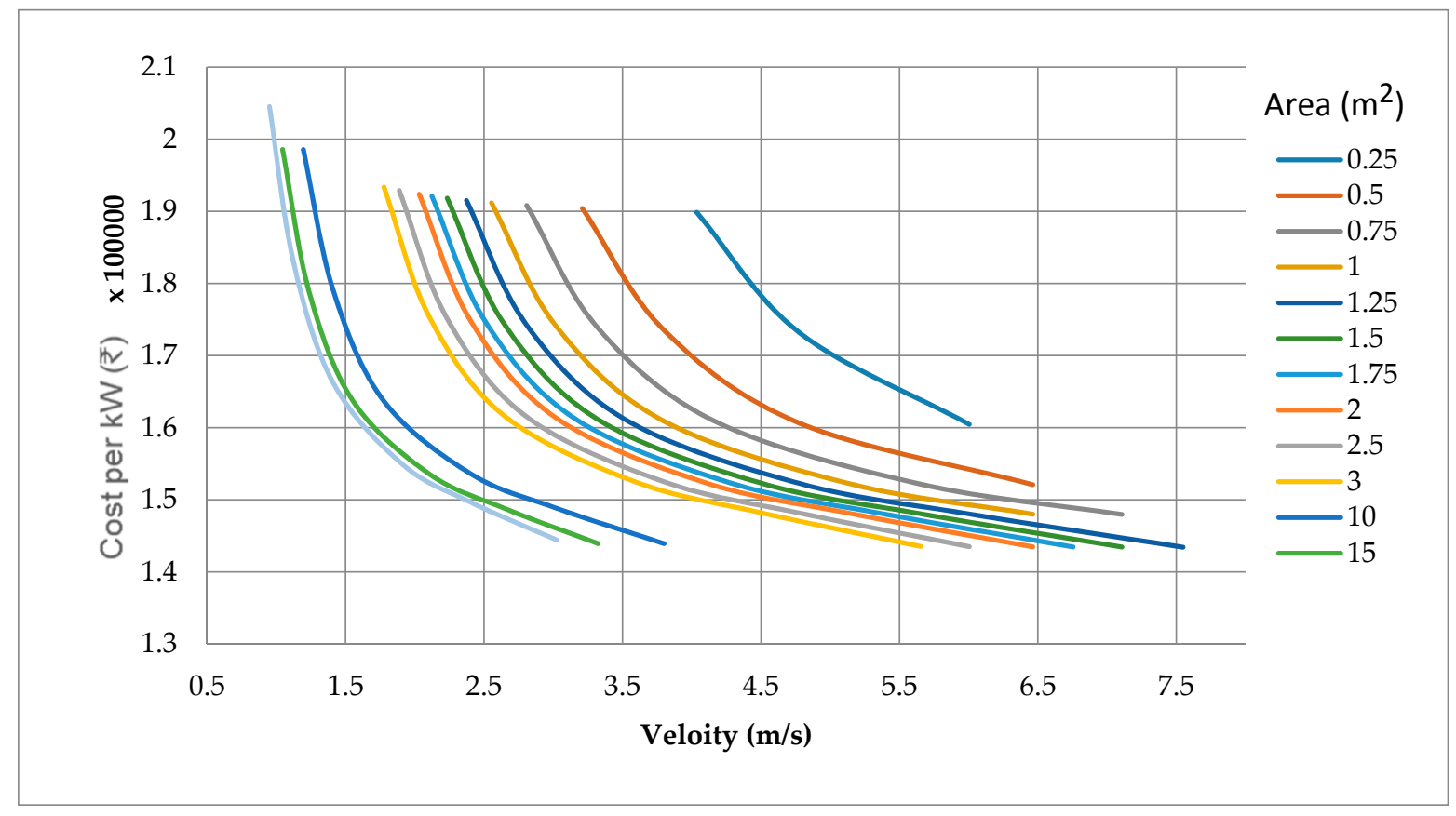

Figure 10. Cost variation of Darrieus turbine with flow velocity at constant frontal area of turbine

Gorlov helical turbine is a Darrieus type turbine with helix blade profile. The coefficient of power is high than Savonius type turbine and it has been taken $\mathrm{Cp}=0.35$. The range of application flow velocity for Gorlov helical turbine is quite similar to other zero head turbines. The cost of Gorlov helical turbine is quite much than the other zero head turbines at same flow velocity. The cost trend of the turbine varies rapidly at low flow velocity (i.e. $1-2 \mathrm{~m} / \mathrm{s}$ ) and constant at higher flow velocity. The low capacity turbine is costly than the high capacity turbine same as for the other zero head turbines. Based on the site parameters that are the velocity of flow, depth of water, it can estimate the power capacity for Gorlov helical turbine as well as the cost of the turbine. The cost per $\mathrm{kW}$ of turbine has reached above 7 lakh at velocity $0.6 \mathrm{~m} / \mathrm{s}$ and area and power of this turbine is $20 \mathrm{~m}^{2}$ and $1 \mathrm{~kW}$. However, it was out of range of the existing Gorlov helical turbine. 


\section{Conclusions}

For techno-economic analysis of small-scale turbines, for different capacities, i.e., 5, 10, 25, 50, and $100 \mathrm{~kW}$ are considered. Analysis has been carried out for Darrieus, Savonius, and Gorlov Helical turbines.

Following conclusions are drawn from the analysis:

- Critical parameters of the zero head turbines are velocity and frontal area of the turbine while head and flow rate are the main parameters for conventional turbines. The cost of turbine mainly depending upon the velocity of flow for a given capacity.

- For low velocity $(<1.5 \mathrm{~m} / \mathrm{s})$, Darrieus, Savonius, and Gorlov helical turbine are not found suitable as these turbines have large frontal area. However, multiple small size turbines as reported in the literature can generate power.

- For typical straight blades, Darrieus turbine of $100 \mathrm{~kW}$ capacity is found the minimum cost of $\quad 143653.5$ for a velocity $5 \mathrm{~m} / \mathrm{s}$. This minimum cost has been found correspond to a rotor height $1.54 \mathrm{~m}$ and radius of $1.15 \mathrm{~m}$.

- In the case of low stream velocity of $1.5 \mathrm{~m} / \mathrm{s}$, Gorlov helical turbine is found economical turbine for a capacity of $100 \mathrm{~kW}$ power, however, a Darrieus turbine of $50 \mathrm{~kW}$ power is economical turbine for a flow velocity of $3 \mathrm{~m} / \mathrm{s}$. For a high stream velocity, Darrieus turbine is found as economical turbine for $100 \mathrm{~kW}$ capacity at $5 \mathrm{~m} / \mathrm{s}$ flow velocity

- For zero head micro hydro turbines range, based on the sizing of hydrokinetic turbines and techno-economic analysis, it is suggested that the Darrieus turbine is a better option to extract zero head potential. However, Gorlov turbine could be a good option for the high-velocity range.

- Based on the study it is recommended to carry out further studies for an optimal sizing of the hydrokinetic turbine for a higher capacity at low water speed.

- It is suggested to carry out an energy analysis for ultra-low and zero head turbines in order to facilitate an optimum installation of micro hydropower system.

Acknowledgments: Authors are thankful to MHRD and MNRE, Government of India, for financial assistance in the form of academic funding for Master of Technology program at Alternate Hydro Energy Centre.

Author Contributions: Anurag Kumar carried out the studies and calculation. Dr. R.P. Saini reviewed and edited the manuscripts.

Conflicts of Interest: The authors declare no conflict of interest

\section{References}

[1]. Thropton Energy, Physic Lane, Thropton, Northumberland NE65 7HU, United Kingdom, January 2010. Available at URL <http://www.throptonenergy.co.uk $>$, (Accessed on May 2014).

[2]. Behrouzi, F., Maimun, a, \& Nakisa, M. (2014). Review of Various Designs and Development in Hydropower Turbines, (2), 87-91.[Gogole Scholar]

[3]. Gorlov, a. M. (2003). The Helical Turbine and its applications for tidal and wave power. Oceans 2003. Celebrating the Past ... Teaming Toward the Future (IEEE Cat. No.03CH37492), 4(6 17), 933957. http://doi.org/10.1109/OCEANS.2003.178204. [Google Scholar] 
[4]. Vertical Axis Hydro Turbine, Available at URL < http://www.bluenergy.com/technology method vaht.html > (Accessed on May-2014).

[5]. Khan, M. J., Iqbal, M. T., \& Quaicoe, J. E. (2006). Design considerations of a straight bladed Darrieus rotor for river current turbines. IEEE International Symposium on Industrial Electronics, 3(2), 1750-1755. http://doi.org/10.1109/ISIE.2006.295835. [Google Scholar]

[6]. Darrieus wind turbine analysis, Available at URL $<\underline{\text { http://windturbine-analysis.com/index.htm. }}$ $>$ (Accessed on May-2014).

[7]. Camporeale, S. M., \& Magi, V. (2000). Stream tube model for analysis of vertical axis variable pitch turbine for marine currents energy conversion. Energy Conversion and Management, 41(16), 1811-1827. http://doi.org/10.1016/S0196-8904(99)00183-1. [Google Scholar]

[8]. Davis, B. V. (1997). Low head tidal power: a major source of energy from the world's oceans. IECEC-97 Proceedings of the Thirty-Second Intersociety Energy Conversion Engineering Conference (Cat. No.97CH6203), 3. http://doi.org/10.1109/IECEC.1997.656 730. [Google Scholar]

[9]. Qinetiq Ltd., "Cycloidal tidal power generation - phase 1," Report for DTI Technology Program, Qinetiq Ltd., UK, Tech. Rep. T/06/00229/REP/1, 2004. Available at URL <http://dnr.alaska.gov/mlw/wslca/appendix j.pdf> (Accessed on May-2014)

[10].Shiono, M., Suzuki, K., \& Kiho, S. (2000). An Experimental Study of the Characteristics of a Darrieus Turbine for Tidal Power Generation. Electrical Engineering in Japan, Vol. 132(No. 3), pp. 38 - 47. http://doi.org/10.1002/1520-6416(200008)132:3<38::AID-EEJ6>3.0.CO;2-E. [Google Scholar]

[11]. Manwell, J. F., McGowan, J. G., \& Rogers, A. L. (2002). Wind Energy Explained: Theory, Design and Application, Wind Engineering. http://doi.org/10.1002/0470846127. [Google Book]

[12]. Archdeacon, TJ. Correlation and regression analysis: a historian's guide.1st ed. Univ. of Wisconsin Press; 1994. [Google Book]

[13]. Singal, S. K., \& Saini, R. P. (2008). Analytical approach for development of correlations for cost of canal-based SHP schemes. Renewable Energy, 33(12), 2549-2558. http://doi.org/10.1016/j.renene.2008.02.010. [Google Scholar]

[14]. Material Properties, Available $\quad$ at $\quad$ URL http://web.mit.edu/course/3/3.11/www/modules/props.pdf.> (Accessed on May-2014). 